\title{
Una interpretación informacional del Niño Salvaje de Aveyron: L'enfant sauvage (1970)
}

\author{
Hans CONTRERAS-PULACHE1,2,3, Alexa Ivonne JOYA QUISPE11, Dafne Solange MOYA-MALDONADO1, 2, \\ Angello Jesús OSCANOA CHÁVEZ1, Yumi Shannon PÉREZ LY1, Jeel MOYA-SALAZAR1,2,4
}

${ }^{1}$ Escuela de Medicina Humana, Facultad de Ciencias de la Salud, Universidad Privada Norbert Wiener, Lima (Perú). ${ }^{2}$ Grupo de Investigación en Neurociencias Aplicadas-GRINA, Universidad Privada Norbert Wiener, Lima (Perú). ${ }^{3}$ Centro de Desarrollo Integral RINCONADA, Lima (Perú). ${ }^{4}$ Hospital Nacional Docente Madre Niño San Bartolomé, Lima (Perú).

Autor para correspondencia: Jeel Moya Salazar. Correo electrónico: jeel.moyasalazar@icloud.com, jeelms@outlook.com

Recibido el 21 de enero de 2019; aceptado el 5 de marzo de 2019.

Cómo citar este artículo: Contreras Pulache H, Joya Quispe Al, Moya Maldonado DS, Oscanoa Chávez AJ, Pérez Ly YS, Moya-Salazar J. Una interpretación Informacional del Niño Salvaje de Aveyron: L'Enfant sauvage (1970). Rev Med Cine [Internet] 2019;15(4): 221-30.

DOI: http://dx.doi.org/10.14201/rmc2019154221230

\section{Resumen}

Sobre la base del film: L'enfant Sauvage (1970) de François Truffaut, se propone discutir los siguientes conceptos: humanización y socialización, desde la perspectiva de la Teoría Sociobiológica Informacional. Y luego, se elabora una interpretación de los cambios que ocurren en el sistema nervioso de un niño salvaje (feral) en el inicio (tardío) de su socialización. En síntesis, buscamos respondernos las siguientes preguntas: i. ¿Qué es lo que busca Itard en Víctor: humanizarlo o socializarlo?; y ii. ¿Cómo puede interpretarse neurológicamente los cambios que le ocurren a Víctor luego de su encuentro con Itard?

Palabras clave: socialización; humanización; neurología; paleocortex; cine; neocortex; Truffaut; L’enfant Sauvage.

\section{An informational interpretation of the Aveyron's Wild Child: L'enfant sauvage (1970)}

Summary

On the basis of the film: L'enfant Sauvage (1970) by François Truffaut, we proposed to discuss the following concepts: humanization and socialization, from the perspective of the Sociobiological Information Theory. And then, we made an interpretation of the changes that occur in the nervous system of a wild (feral) child at the (belated) inception of its socialization. In summary, we seek to answer the following questions: I. what is Itard looking for in Víctor: humanize it or socialize it? And, II. How can the changes that happen to Victor after his encounter with Itard be interpreted neurologically?

Keywords: socialization; humanization; neurology; paleocortex; cinema; neocortex; Truffaut; L'enfant Sauvage. 


\section{Ficha técnica}

Título: El Pequeño Salvaje (Hispanoamerica) / The Wild Child.

Título original: L'enfant sauvage.

País: Francia.

Año: 1970.

Director: François Truffaut.

Música: Antonio Vivaldi.

Fotografía: Néstor Almendros (como Nestor Almendros).

Montaje: Agnès Guillemot.

Guión: François Truffaut \& Jean Gruault (escenario, adaptación y diálogo), Jean Itard.

Intérpretes: Jean-Pierre Cargol (Victor, l'enfant sauvage), François Truffaut ( $\mathrm{Dr}$ Jean Itard), Françoise Seigner (Madame Guerin), Jean Dasté (Professor Philippe Pinel), Annie Miller (Madame Lemeri), Claude Miller (Monsieur Lemeri), Paul Villé (Remy), Nathan Miller (Baby Lemeri), Mathieu Schiffman (Mathieu), Jean Gruault (Visitor at Institute),...

Color: blanco y negro.

Duración: 83 minutos.

Género: drama.

Productoras: Les Artistes Associés, Les Films du Carrosse, Les Productions Artistes Associés.

Sinopsis: "Película basada en hechos reales acontecidos a finales del siglo XVIII. Narra el proceso de educación de un niño (Jean-Pierre Cargol) que creció aislado en el bosque sin contacto alguno ni con los hombres ni con la civilización, que bajo la supervisión del Dr. Jean Itard (François Truffaut) descubrirá lo que es vivir bajo los márgenes estrechos que ofrece la civilización parisina, apartándose de la vida libre que le ofrece la naturaleza; siendo como un portal entre el interior cerrado y el mundo exterior, las ventanas de su nueva casa. A pesar de todo ello, Victor (el niño salvaje), logra adaptarse a la enseñanza impartida por su tutor (Jean Itard), que no llega a cumplir su objetivo al cien por ciento; observando la evolución de su transformación. Una de las películas más celebradas de Truffaut" (FilmAffinity).

Premios: 1970: Seminci: Lábaro de Oro: Mejor película y Círculo de Críticos de Nueva York: Nominada a Mejor guión.

\section{Enlaces:}

https://www.imdb.com/title/tt0064285/?ref =nv sr 1

https://m.filmaffinity.com/es/movie.php?id=634722

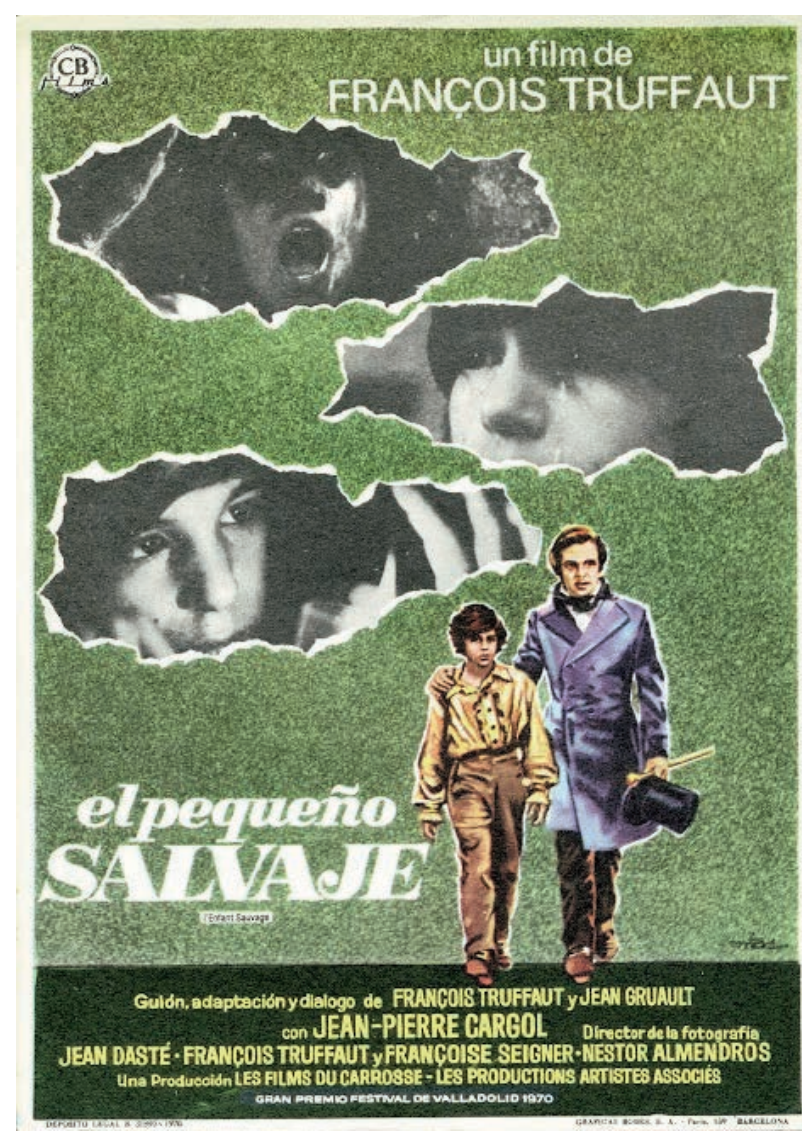

Cartel español

Trailer

El cine en el aprendizaje médico

La tecnología nos está dotando de herramientas, prótesis, extensiones, añadiduras, útiles y peligrosas, ya cotidianas para la humanidad, que de manera masiva están presentes en muchas comunidades, siendo determinantes irreversibles que pueden cambiar las herencias milenarias, los hábitos culturales y el entendimiento de la realidad. Esta naturaleza tecnoprotética que es propia de nuestra especie resalta la artificiosidad del ser humano ${ }^{1}$.

El desarrollo tecnológico nos ha llevado a una era irreversible que presenta bondades y riesgos para la humanidad. Esta tecnología puede verse reflejada en cada aspecto humano contemporáneo, pero es en la educación, tanto de los inmigrantes como de los nativos tecnológicos, donde puede generar cambios divergentes nunca antes vistos ${ }^{2}$.

La influencia de estos medios masivos de comunicación ha permitido y permite grandes avances en la educación principalmente en los países con altos ingresos ${ }^{3}$. 
La medicina se ha beneficiado de estos avances tecnológicos. Está disciplina sanitaria, se ha valido de múltiples herramientas como las series, programas de televisión e inclusive películas para explicar los fenómenos que acontecen en este ámbito relacionado a la salud humana a fin de prevenirla, protegerla, diagnosticarla y tratarla. En ese sentido, se han referidos estudio relacionados con medicina clínica ${ }^{4,5}$, ciencias básicas ${ }^{6,7}$, profesionalismo médico ${ }^{8-11}$, neurología12,13, epidemiología14,15, dermatología16, infectología ${ }^{17}$, geriatría18, entre otros, donde se ha utilizado el arte del cine y la televisión para explicar críticamente mediante modelos teóricos y prácticos las bondades de la medicina en el contexto de la enfermedad ${ }^{19}$. Así, esta propuesta es una forma novedosa y aguda de desarrollar y afianzar los conceptos ofrecidos por la medicina, y no solo en ella sino, trascendiendo a otros campos que pueden oscilar desde la educación escolar inicial a la formación superior humana.

En ese sentido, reconocemos el aporte benéfico que posee, y a través de sus beneplácitos presentamos un análisis de la película L'enfant sauvage dirigida por François Truffaut, que tiene el propósito de exhibir en forma de preguntas dos proposiciones sobre el desarrollo de Víctor (el niño salvaje) desde una argumentación neurológica. Bajo esta intención explicamos cada uno de los puntos vinculados con el tema, para luego escudriñar nuestras respuestas desde el enfoque de la interpretación informacional.

\section{Humano salvaje vs Humano social}

Es necesario definir "humano salvaje" como aquel sujeto individual, Homo sapiens o "ser humano" (a secas) que crece al margen de la sociedad. Para esto, se considera que la sociedad es aquella estructura material significativamente histórica (de por lo menos $30 \mathrm{mil}$ años) que existe y envuelve a las personas. En este sentido, cada ser humano que nace en sociedad, incorpora de ésta la información social sobre la cual desarrollará su actividad personal. Por lo tanto, un "humano salvaje" será un ser humano que no ha llegado a desarrollar su conciencia debido a que durante un periodo de tiempo de su vida se ha encontrado al margen de la sociedad. Un humano salvaje podría considerarse como un ser vivo natural, que no ha sido artificializado (si la sociedad es la construcción histórica del ser humano, la sociedad es una entidad artificial) ${ }^{2,20}$. En otras palabras, la presencia de la sociedad hace trascender la condición natural por lo que el ser humano socializado no es otro más que el Homo sapiens que goza de la existencia de lo artificial y en su seno establece sus propios grados de libertad.
Cada vez que nace un ser humano no nace en el aire, nace en el seno de una familia (esta familia, y su organización funcional o disfuncional, es considerado su sociedad), luego transita por sistemas sociales institucionalizados como la cuna, el jardín, la escuela primaria, secundaria, la universidad el mundo laboral, entre otros. Esta serie de pasos, no es otra cosa más que la socialización, es decir, cómo la sociedad da forma al ser humano.

En el caso de un "humano salvaje" justamente lo que falta es esta información; ya que, al no haber sociedad, o más precisamente, al crecer al margen de la sociedad, no logra establecer el modelamiento característico de toda persona: la naturaleza artificial de nuestra "mente". Así, la "mente" de un humano salvaje será la que caracterice a los individuos inconscientes (los mamíferos en general) mientras que la "mente" del humano socializado será la que caracterice a los individuos conscientes (las personas en sociedad). Un "humano salvaje" presenta necesidades biológicas que busca satisfacer en su entorno inmediato (en su entorno natural), mientras que las personas presentan necesidades sociales que buscan satisfacer ya no en su entorno inmediato sino en toda la estructura de la sociedad a la que se puede tener acceso (este "entorno" ya no es natural sino artificial).

\section{Niños salvajes}

La evidencia ha descrito varios casos de "humanos salvajes" también conocidos como "niños salvajes", "niños ferales". Por ejemplo, tenemos el caso de Marina Chapman (nacida en Colombia en 1940) quien fue secuestrada a los 5 años y abandonada en la jungla, ahi se juntó con monos capuchinos los cuales reemplazaron el papel de una familia y ella aprendió de estos animales todo tipo de comportamientos como trepar, comer, hacer ruidos, etc. Por otro lado, tenemos el caso de Oxana Malaya (nacida en Ucrania en 1983) quien en su infancia, alrededor de los 3 años, empezó a vivir con perros vagabundos a causa de abandono por sus progenitores e igualmente se halló el mismo patrón de comportamiento en un ambiente ausente de artificialización, hallándola ladrando, movilizándose mediante sus cuatro extremidades, comiendo carne cruda y con particular agresividad a las personas. Por último, el caso del llamado "El salvaje de Aveyron", posteriormente nombrado "Víctor", trata sobre un niño salvaje hallado en Francia alrededor de 1784 con apariencia de once años, en este se evidenció el lamentable infortunio del intento de asesinato a través de un corte en el cuello, el cual no fue capaz de acarrear su muerte, y abandono en el bosque por alrededor de 7 años; por lo tanto, se cumplen las condiciones de que al no poseer un entorno social que brinde la artificialización conlleva a 
no determinarse como un humano social; a causa de ello, es que al encontrarlo fue un feral que sólo vivía según el instinto de supervivencia, no sabía hablar, ni escribir y no poseía el "raciocinio" suficiente para poder llevar a cabo actividades como ser social.

Vamos a precisar en este trabajo el caso de Victor, a propósito de la película L'enfant sauvage de François Truffaut (1970). En este film, el protagonista es Víctor, un "humano salvaje" (Foto 1) que ha crecido en un entorno completamente natural y que al ser encontrado en los alrededores de un pueblo (bosque) pasa a vivir en un contexto artificial de manera abrupta (completamente nuevo para él). Hubo un mediador, el médico Jean Itard (1774-1838), cuya ideología era que el ser humano es el resultado de un programa constructivo. Es así, como Itard decide proporcionarle herramientas e instrumentos necesarios en su proceso de artificialización durante una supervisión continua en su propio hogar. A través de sus escritos, Itard nos permite conocer el progreso secuencial que Víctor va teniendo a través de los días, desde la conducta salvaje hasta el logro del aprendizaje básico (cambiarse de ropa, utilizar cubiertos, identificar objetos, expresar emociones, etcétera) a través de la imitación.

\section{Pregunta 1: ¿qué es lo que busca Itard en Víctor: huma-} nizarlo o socializarlo?

No vamos a llegar muy lejos si asumimos los conceptos de "humanización" y "socialización" solo como verbos que quieren decir, el primero: "acción y efecto de humanizar o humanizarse", y el segundo: "acción y efecto de socializar", tal como nos sugiere el Diccionario de la Real Academia de la Lengua. Desde esta posición simplista podría decirse resumidamente que Víctor empieza a socializar y por lo mismo nace su humanidad. Sin embargo, si asumimos para estos conceptos (humanización y socialización) definiciones más rigurosas, podemos ir más allá al momento de elaborar nuestra respuesta. A continuación vamos a interpretar lo visionado en el film desde una posición teórico informacional, o lo que es lo mismo: desde la Teoría Sociobiológica Informacional (TSI) ${ }^{21}$.

El desarrollo del ser humano hasta su momento actual (el "hombre" moderno) ha seguido varias etapas que es preciso no pasar por alto. De un modo sintético diremos que hemos llegado, nosotros: los seres humanos modernos, hasta donde estamos actualmente sobre la base de haber transitado: a) primero por la hominización (proceso que podríamos concluir con el establecimiento del Homo sapiens, que principió hace varios millones de años y que concluye aproximadamente 200 mil años antes de nuestra era); b) luego, por la humanización (el

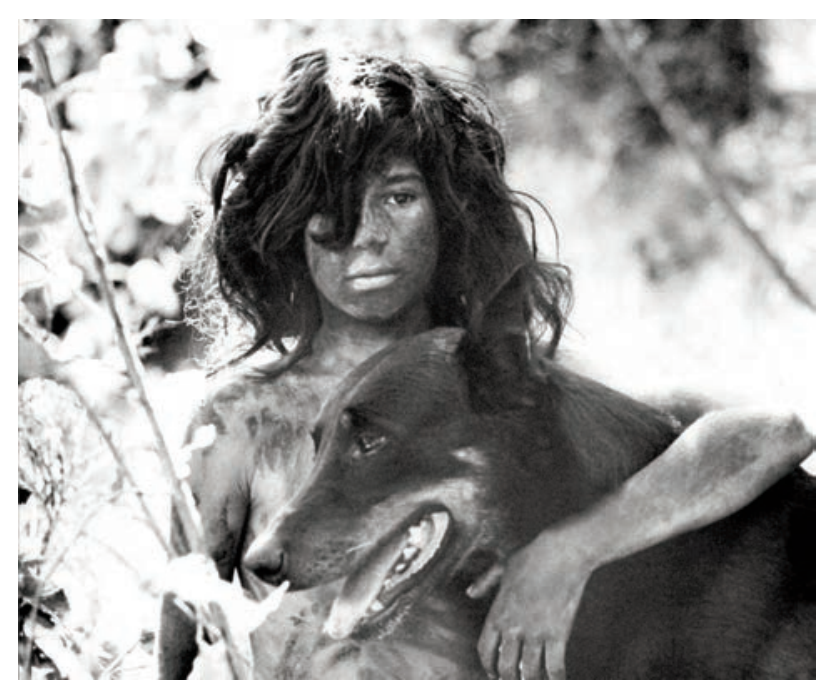

Foto 1. Víctor antes de su encuentro con Itard. Su condición de "niño salvaje" representa la vida de un Homo sapiens condenado a no gozar la libertad de poder vivir en sociedad (creando (afuera) y recreando (dentro de sí) información social).

establecimiento del Homo sapiens llevó al nacimiento de la humanidad); y c) finalmente por la socialización (que implica el nacimiento de la sociedad: la humanidad funda la sociedad). Para explicarnos mejor, vamos a descartar la definición tradicional según la cual el ser humano es social porque es sociable (porque vive en grupos, porque es colectivo, porque existe para o junto a otro u otros, etcétera).

Al amparo de esta definición se suele decir que el ser humano es social porque vive en colectivos, porque goza de "socialidad" (valga el neologismo). Así, lo social es un adjetivo, y por lo mismo se puede extender a las hormigas, las abejas, y muchos mamíferos (que se dicen, en síntesis: animales sociales). Es más, desde esta forma de ver las cosas: la socialización como rasgo típico del ser humano es lo que funda su humanización (de ahí que la humanización y socialización a veces no vean claramente diferenciadas sus diferencias). Desde nuestra interpretación informacional, la humanización y la socialización son dos momentos progresivos en la historia del desarrollo del ser humano en el curso de los últimos 200 mil años. La diferencia entre ambas es de suma importancia. El producto de la humanización son los seres humanos: y su capacidad profunda (arraigada, obviamente, en su sistema nervioso en general y en su cerebro en particular) por la vida humana (aquí se pueden enlistar todos los rasgos diferenciales fenoménicos y órgano-estructurales que diferencian al Homo sapiens del resto de homínidos que existieron sobre la tierra en algún espacio del tiempo). El producto histórico de la socialización ya no son los seres humanos (la humanización consistió en última instancia 
en una complejización que ocurrió dentro de la cabeza) sino la sociedad (algo que, claramente definida, se encuentra fuera de la cabeza de los seres humanos).

Desde la perspectiva informacional, la sociedad es una estructura material significante que se encuentra fuera de los seres humanos, históricamente acumulada y situada contextualmente de tal modo que alberga y cobija a cada ser humano que nace. Es justamente el proceso de socialización el que determina el nacimiento de la sociedad, y al mismo tiempo algo mucho más trascendente: la obligación ontológica de todo ser humano que nace en sociedad de incorporarla dentro de su cabeza, fundando así su condición completa de ser humano moderno. Desde la TSI diremos que la información social es la base de la estructura de la sociedad y es al mismo tiempo la base de los procesos psíquicos superiores que son los fundantes de la naturaleza misma del ser humano actual. Nacemos sociales no porque seamos humanos, sino porque habiendo trascendido esta humanidad presentamos una vocación inenarrable hacia la incorporación de la información social con la cual nos encontramos luego (incluso antes) de nuestro nacimiento.

Existe el concepto de Homo sapiens, para designar al ser humano moderno, el cual desde nuestro particular punto de vista entonces situaremos como el fundador ya no de la humanización (desde hace 200 mil años) sino de la socialización (desde hace por lo menos 30 mil años). Por tanto, todo ser humano moderno que nace actualmente (o hace un poco más de dos siglos como el caso de Víctor) es un Homo sapiens porque nace en el momento histórico en que existe la sociedad. Este Homo sapiens posee las capacidades suficientes para socializar, es decir para crear sociedad y para incorporar a la sociedad preexistente en sus redes neurales de máxima complejización.

Estos serían por tanto los rasgos esenciales de la condición humana moderna: creación e incorporación de sociedad. Visto así, vamos a respondernos nuestra pregunta. Víctor es un Homo sapiens, por ende no es posible humanizarlo. Su condición humana no está en tela de juicio: nació en el siglo XVIII y no hace 100 mil años. Por tanto le ocurra lo que le ocurra no podrá llamarse a ello humanización simple y llanamente porque pertenece a un linaje histórico que ya transitó la humanización hace muchos miles de años atrás.

En tanto Homo sapiens, Víctor, nace en sociedad, sin embargo, pronto se ve exiliado de esta. Su aislamiento lo condena a una incompletude humana: no goza la capacidad de su condición, no crea información social ni incorpora la información social ya existente. Por lo mismo, Itard lo que está haciendo es socializar a Víctor, y decimos socializar en el sentido de hacerlo nacer en la sociedad: de otorgarle la libertad social de crear sociedad y de incorporarla. En este sentido, y a contracorriente de lo que vulgarmente podría suponerse, nos parece más correcto afirmar que Itard no estaba buscando humanizar a Víctor, sino buscaba socializarlo. Y, repetimos, busca socializarlo en tanto despliega una serie de estrategias para que Víctor pueda incorporar la información social que durante la primera y única década de su vida se perdió. Para mayor precisión sobre las diferencias entre humanización (y hominización) y socialización se muestra una síntesis de la explicación informacional de estos procesos en la Tabla 1, 2 y 3.

Pregunta 2: ¿cómo puede interpretarse neurológicamente los cambios que le ocurren a Víctor luego de su encuentro con Itard?

Según el modelo clásico del sistema nervioso humano el cerebro es la cima estructural del encéfalo y la médula espinal (que son las partes constituyentes del llamado: sistema nervioso central). Este sistema nervioso central envuelve orgánicamente al llamado sistema nervioso periférico (que es el que en última instancia determina sobre todos los órganos del cuerpo humano). Este modelo clásico se inspira en el conocimiento anatómico del cadáver que nutrió a la neurología en sus inicios. Ciertamente, en la actualidad, mucho de los que se sabe sobre el sistema nervioso se encuentra fuertemente arraigado en la visión anatómica del cadáver. Por ejemplo, la noción de sustancia gris/sustancia blanca, la noción de los lóbulos cerebrales. Más específicamente: en los inicios del siglo XX se propuso que en el cerebro existía una citoarquitectura tan específica que era factible diferenciar alrededor de 50 áreas en cada hemisferio (se llegó a esta conclusión luego de estudiar microscópicamente muchos cerebros de cadáveres humanos y animales).

Esta fue la propuesta del neurólogo patólogo Emile Broadmann, que 100 años después (como para corroborar nuestra afirmación: "mucho de los que se sabe sobre el sistema nervioso se encuentra fuertemente arraigado en la visión anatómica del cadáver"), en Nature (2016) se publicó un artículo en el cual se afirmaba que cada hemisferio tiene 180 áreas funcionales diferenciadas $^{25}$. La diferencia entre estos conocimientos un siglo distantes, radica en que para el siglo XX solo se disponía de técnicas para estudiar a los cadáveres mientras que actualmente se dispone ya de tecnología suficiente para explicar al sistema nervioso del ser humano vivo. Esto ha 
Tabla 1. Síntesis informacional de la hominización, humanización y socialización $21-25$.

\begin{tabular}{|c|c|c|c|c|c|}
\hline $\begin{array}{l}\text { Desarrollo } \\
\text { evolutivo }\end{array}$ & Descripción & Desde & Hasta & Individuos & Estructuración del cerebro \\
\hline Hominización & $\begin{array}{l}\text { Establecimiento de la familia } \\
\text { Hominidae. } \\
\text { Cambios corporales: bipedes- } \\
\text { tación, reorganización orgá- } \\
\text { nica (manualidad, acorta- } \\
\text { miento de pelvis, fonación). } \\
\text { Producción de utensilios } \\
\text { (hace 2,5' años). } \\
600 \text { cc: encéfalo }\end{array}$ & $\begin{array}{l}\text { Hace } 7 \\
\text { millones } \\
\text { de años }\end{array}$ & $\begin{array}{l}\text { Hace } 700 \\
\text { mil años }\end{array}$ & 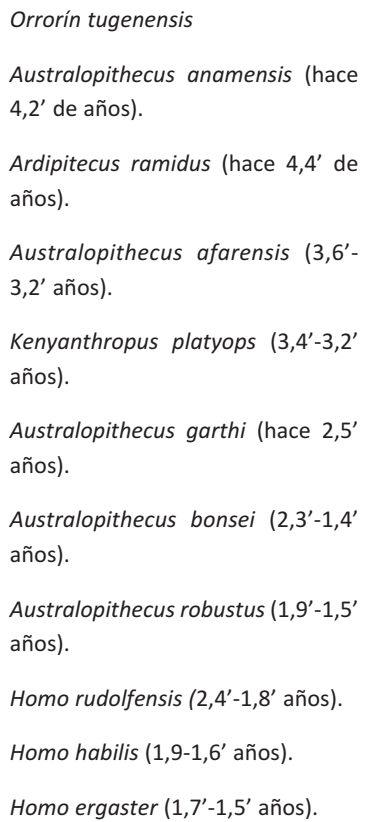 & $\begin{array}{l}\text { La determinación epigenética } \\
\text { lleva hasta la estructuración del } \\
\text { paleocórtex. } \\
\text { El individuo y sus sensaciones } \\
\text { (viscerales y somáticas). } \\
\text { No hay neocórtex. } \\
\text { El paleocórtex (P1 y P2) se inte- } \\
\text { gra ejecutiva y anticipatoriamen- } \\
\text { te. } \\
\text { La comunicación es enteramente } \\
\text { por señales. } \\
\text { Solo existe información psíquica } \\
\text { inconsciente: sensaciones. }\end{array}$ \\
\hline
\end{tabular}

P1: corteza parahipocámpica y cingular. P2: corteza heterotípica (sentiva tactil auditva, gustativa y motora primaria).

N1: corteza de asociación orbitofrontal y temporal anterior. N2: corteza de asociación temporoparietooccipital. N3: corteza de asociación prefrontal dorsolateral y medial.

llevado actualmente a que el modelo clásico para entender al sistema nervioso humano se vea renovado, fuertemente, en el curso del último medio siglo. No cabe duda que las neurociencias han jugado un papel clave en este desarrollo. Es justamente en este contexto de búsqueda y elaboración de un modelo explicativo del sistema nervioso humano de una persona (valga la redundancia) viva, es que a finales del siglo XX se propuso la explicación informacional del sistema nervioso humano. Esta explicación forma parte de la Teoría Sociobiológica Informacional (TSI), desarrollada por Pedro Ortiz Cabanillas, y que sobre la base de proponer una definición distinta de "información" elabora una explicación de la relación entre el universo, la sociedad y el cerebro humano 21 . A saber de los autores, este es el primer modelo del sistema nervioso que logra resolver el problema mente-cerebro. Es justamente desde esta posición informacional que explicaremos la neurología de Víctor, como respuesta a nuestra segunda pregunta.

Como decíamos para la primera pregunta: la socialización es el proceso mediante el cual el ser humano moderno inventa la información social y con lo mismo: la sociedad. Desde esta perspectiva la sociedad no es el conjunto de personas sino una estructura material envolvente, creada por el ser humano moderno en el curso de los últimos, por lo menos, 30 mil años. Podríamos aplicar aquí sin problemas el término: "artificialeza" (valga el neologismo) para describir la esencia de la información social y de la sociedad. También, cada ser humano que nace debe incorporar en su cerebro dicha información social (por lo menos la parte a la que contextualmente llega a tener acceso). Para lograr esta socialización, al momento de nacer, el ser humano cuenta con una serie de estructuras neurales que reflejan realidades psíquicas. Informacionalmente (precisamos que las definiciones que vamos a tomar no se deben asumir desde otra posición teórica (entiéndase, por ejemplo: psicoanálisis) sino entera y únicamente desde una postura informacional) se puede decir que el cerebro humano se estructura a dos niveles: el nivel inconsciente (paleocortical) y el nivel consciente (neocortical). La información social, específicamente tendrá su asiento en el nivel consciente (neocortical). Es decir: 
Tabla 2. Síntesis informacional de la hominización, humanización y socialización $21-25$.

\begin{tabular}{|c|c|c|c|c|c|}
\hline $\begin{array}{c}\text { Desarrollo } \\
\text { evolutivo }\end{array}$ & Descripción & Desde & Hasta & Individuos & Estructuración del cerebro \\
\hline Humanización & $\begin{array}{l}\text { Establecimiento del género } \\
\text { Homo. } \\
\text { Conjuntos de miembros des- } \\
\text { arrollan colectivos humanos. } \\
\text { Existen muchas formas de } \\
\text { humanidad. } \\
\text { "Los procesos de humanización } \\
\text { ocurrieron en varias especies de } \\
\text { Homo" } \\
\text { Es enteramente colectiva. } \\
\text { Uso del fuego. } \\
\text { Uso y producción de utensilios. } \\
\text { Uso de vestimenta. } \\
\text { Recogen alimentos. Nómades. } \\
\text { Caza animales. Vive en cuevas. } \\
\text { Entierra a sus muertos. } \\
\text { Cocina sus alimentos. } \\
\text { Se comunica por señales, com- } \\
\text { plejiza la comunicación oral pero } \\
\text { sin articular palabras. }\end{array}$ & $\begin{array}{l}\text { Hace } 700 \\
\text { mil años }\end{array}$ & $\begin{array}{l}\text { Hace } 70 \\
\text { mil años }\end{array}$ & $\begin{array}{l}\text { Homo erectus ( } 1,7^{\prime}-250 \text { mil años). } \\
\text { Homo antecesor (hace } 800 \text { mil } \\
\text { años). } \\
\text { Homo neanderthalensis ( } 200 \text { mil- } \\
30 \text { mil años). } \\
\text { Homo denisova y Homo soloensis } \\
\text { (hasta hace } 50 \text { mil años). } \\
\text { Homo floresiensis (hasta hace } 12 \\
\text { mil años). }\end{array}$ & $\begin{array}{l}\text { La determinación epigenética } \\
\text { lleva hasta la estructuración del } \\
\text { neocortex de transición.El indivi- } \\
\text { duo integra sus sensaciones en } \\
\text { simbolismos. } \\
\text { Ya no solo se anticipa y ejecuta, } \\
\text { incluso se organiza en colectivos, } \\
\text { probablemente no mayores a } \\
150 \text { personas. } \\
\text { Se comunica sin palabras, usan- } \\
\text { do gestos y oralidad. } \\
\text { No existe información social. } \\
\text { Solo existe información psíquica } \\
\text { inconsciente complejizada pre- } \\
\text { conscientemente pero aun no se } \\
\text { inventa la información social } \\
\text { (que permitirá trascender el } \\
\text { nivel inconsciente a un nivel } \\
\text { consciente). }\end{array}$ \\
\hline
\end{tabular}

la información social, todo lo que una persona incorpora a lo largo de su vida, da forma al neocortex (la corteza cerebral de transición y de asociación en ambos hemisferios). Adicionalmente, para que el neocortex tome forma a la luz de la información social, existe una interfaz en el cerebro llamada preconsciencia.

La preconsciencia incluye a todas las áreas para el lenguaje en el hemisferio izquierdo (comúnmente llamadas áreas de Broca, Wernicke, Luria, Exner y Dehaene) y también del hemisferio derecho (las cuales de plano no son ni estudiadas ni reconocidas por quienes siguen el modelo clásico del sistema nervioso según el cual el "lenguaje" es un atributo del hemisferio izquierdo). La preconciencia es una estructura psíquica cuya significación será la de permitir el paso de información psíquica inconsciente (de naturaleza ambiental: natural) en información psíquica consciente (de naturaleza social: artificial). La preconsciencia permite que ciertas sensaciones (táctiles, auditivas, visuales) se complejicen bajo la forma de símbolos, de signos (dejando así la realidad sensorial y permitiendo el establecimiento de la realidad significante, social, consciente). Sobre la base de la actividad preconsicente toma forma el neocortex, como asiento de la conciencia, permitiendo así la existencia de la información social (ya sea adentro de la cabeza, bajo la forma de actividad consciente, ya sea fuera de la cabeza, bajo la forma de sociedad).

Siguiendo esta explicación informacional podemos afirmar que Víctor en el proceso de socialización que le imprime Itard, va a ver reorganizado todo su sistema nervioso, en particular su cerebro (Foto 2). Podemos imaginar que las áreas sensoriales primarias (paleocortex) empiezan a reorganizarse a la luz del descubrimiento de la información social (por eso antes no reconoce el sonido de una puerta pero sí el de un alimento cayendo al piso). Es probable que también a estos niveles de sensorialidad y motricidad primaria pudiéramos ubicar que Víctor aprenda a reconocer los símbolos (martillo, llave, tijera), y los signos (las letras, herramientas que por otra parte no nos hacen olvidar la presencia de María Montessori, quien leyó profundamente a Itard y sobre el cual ideó los pilares fundamentales de su "Método". Lamentablemente, el tiempo quiso que María Montesori no llegara a ver la película de Truffaut, Montesori murió mucho antes que el cine existiera como experiencia hegemónica, pero creemos, firmemente, que de haber visto la 
Tabla 3. Síntesis informacional de la hominización, humanización y socialización 21-25.

\begin{tabular}{|c|c|c|c|c|c|}
\hline $\begin{array}{l}\text { Desarrollo } \\
\text { evolutivo }\end{array}$ & Descripción & Desde & Hasta & Individuos & $\begin{array}{l}\text { Estructuración del cere- } \\
\text { bro }\end{array}$ \\
\hline Socialización & 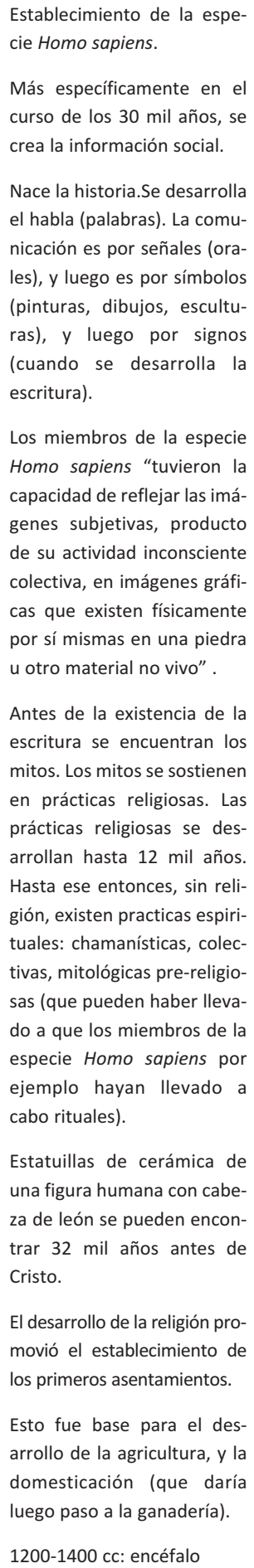 & $\begin{array}{l}\text { Hace } 70 \text { mil } \\
\text { años } \\
\text { Más esen- } \\
\text { cialmente } \\
\text { hace } 30 \text { mil } \\
\text { años } \\
\text { Entre hace } \\
70 \text { y } 30 \text { mil } \\
\text { años tuvo } \\
\text { lugar la } \\
\text { "revolución } \\
\text { cognitiva": } \\
\text { aparecen por } \\
\text { primera vez: } \\
\text { leyendas, } \\
\text { mitos, dio- } \\
\text { ses, y religio- } \\
\text { nes. }\end{array}$ & $\begin{array}{l}\text { Actualidad } \\
\text { Hipót esis } \\
\text { informacio- } \\
\text { nal: existen- } \\
\text { cia de la } \\
\text { sociedad } \\
\text { por lo } \\
\text { menos en } \\
\text { los últimos } \\
30 \text { mil años. }\end{array}$ & $\begin{array}{l}\text { Arte rupestre: hace } 40 \text { mil años. } \\
\text { Centros religiosos: hace } 12 \text { mil años. } \\
\text { Primeros establecimientos: hace } 10 \text { mil } \\
\text { años.Revolución agraria: hace } 7-9 \text { mil } \\
\text { años. } \\
\text { Primeros asentamientos (propiedad } \\
\text { privada): hace } 7-9 \text { mil años. } \\
\text { Escritura: } 3 \text { mil años antes de Cristo. } \\
\text { Filosofía: Mil años antes de Cristo. } \\
\text { Revolución científica: hace } 500 \text { años. }\end{array}$ & $\begin{array}{l}\text { La terminación epigenética } \\
\text { lleva hasta la estructuración } \\
\text { del neocortex de asociación: } \\
\text { N1, N2 y N3. } \\
\text { Existe la información social y } \\
\text { existe la información psíqui- } \\
\text { ca consciente. } \\
\text { Hipótesis informacional: } \\
\text { N1: desde hace } 30 \text { mil años. } \\
\text { N2: desde hace } 5 \text { mil años. } \\
\text { N3: desde hace } 500 \text { años. } \\
\text { El neocortex puede incorpo- } \\
\text { rar información social. Debe } \\
\text { socializarse }\end{array}$ \\
\hline
\end{tabular}

P1: corteza parahipocámpica y cingular. P2: corteza heterotípica (sentiva tactil auditva, gustativa y motora primaria).

N1: corteza de asociación orbitofrontal y temporal anterior. N2: corteza de asociación temporoparietooccipital. N3: corteza de asociación prefrontal dorsolateral y medial. 


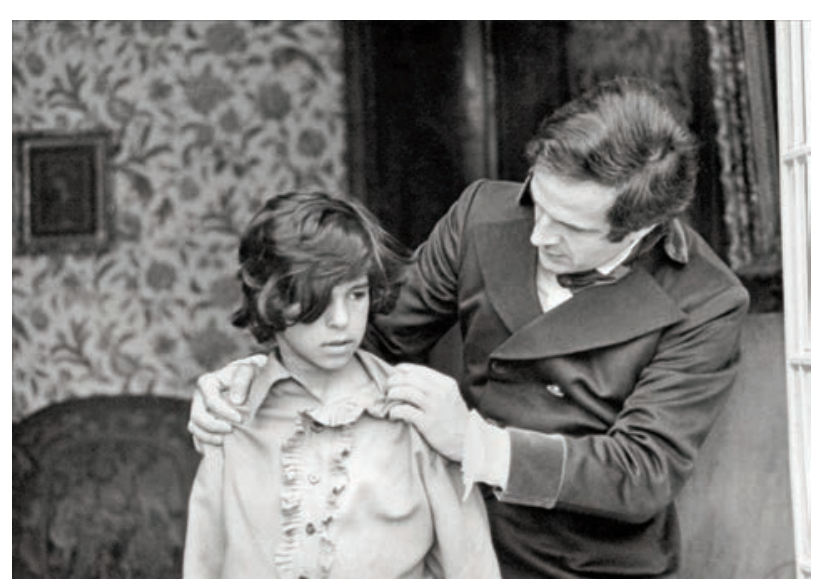

Foto 2. Víctor, durante su socialización, es conducido por Itard a su encuentro con la información social: normas, signos, símbolos, sonidos. Itard está construyendo la mente de Víctor, en tanto definamos por mente a toda la experiencia social que acumula una persona a lo largo de su vida social.

película, se encontraría gustosa de ver que muy probablemente Truffaut imaginó los instrumentos de Itard sobre la base de lo que ella misma se encargó de socializar (en el sentido de crear información social) en el mundo). La capacidad de comprender el lenguaje hablado, más que los contenidos: la forma del lenguaje hablado, está reconfigurando las áreas derechas de la preconsciencia. Al mismo tiempo la búsqueda del entendimiento de las órdenes (que pasa por decodificar las palabras del habla) pasa por una reconfiguración de las áreas izquierdas de la preconciencia. El aprendizaje de las normas de convivencia, de los procesos de razonamiento lógico, de conceptos, implicaría una reorganización que situaríamos en el neocortex, en ambos hemisferios cerebrales. En este sentido, la socialización que vive Víctor se vería reflejada como cambios en todo su cerebro, a nivel paleocortical (en sus áreas sensoriales y motrices primarias), a nivel preconsciente (en sus áreas corticales de transición derecha e izquierda) y a nivel neocortical (en sus áreas de corticales de asociación). Estos cambios van a determinar hacia epigenéticamente la posibilidad de crear información psíquica consciente (representarse el mundo propio y el mundo circundante) y hacia sociocinéticamente la posibilidad de crear información social (como habla, dibujo, escritura, o actos sociales significantes).

\section{Conclusiones}

El cine representa una herramienta pedagógica que puede ser usada como vehículo para enseñar diversos aspectos de la medicina a estudiantes en formación. En particular, lo que hemos demostrado es el uso de una película para enseñar conceptos sobre antropología médica y sobre neurología.
Actualmente existen, por lo menos, dos formas de entender al sistema nervioso humano, el modelo clásico (inspirado en el estudio de los cadáveres) y el modelo informacional (basado en la TSI). Es preciso resaltar que la TSI no representa el único esfuerzo para hacer que la neurología explique solo al cadáver sino al ser humano vivo. Sin embargo, la TSI representa el primer esfuerzo por ir más allá de la explicación del cerebro solamente, buscando integrar en un solo marco explicativo: el universo, la sociedad y el cerebro humano.

Itard lo que hizo fue socializar a Víctor, no humanizarlo. Es decir: buscó integrar a Víctor en el orden de la sociedad (y por tanto brindarle la oportunidad de gozar creando y recreando información social).

Los cambios neurológicos que vive Víctor se puede rastrear a lo largo de toda su corteza cerebral, en sus dos hemisferios, siguiendo un proceso secuencial en términos constructivos, desde lo paleocortical a lo neocortical, pasando por la interfaz de la preconsciencia. Es probable que dada las condiciones de neuroplasticidad, los esfuerzos de Itard no se vieran (tal como sucedió en la vida real) totalmente logrados. En este sentido la socialización incompleta que logró Víctor podría deberse a lo tardío de su inicio o a alguna determinación epigenética presente al momento de su nacimiento (el hecho de presentar alguna condición neurológica como autismo, por ejemplo, que se ha propuesto como una hipótesis explicativa del motivo de su abandono).

Informacionalmente, la determinación epigenética está representada por la capacidad organizativa del sistema nervioso desde lo celular hasta lo neocortical. No es, como en el enfoque clásico moderno, una modificación de las proteínas histona. A esta "determinación epigenética", del enfoque clásico moderno, desde una perspectiva informacional se le consideraría como una de las últimas manifestaciones de la determinación cinética. La determinación cinética sigue la ruta inversa de la determinación epigenética (va desde lo neocortical a lo celular). Así, informacionalmente, el sistema nervioso se integra epigenética y cinéticamente. Si en una persona existe un problema en la organización de la célula (por ejemplo por falla genética o "epigenética" (a nivel de proteínas histona)), esto configurará una afectación de la determinación epigenética del sistema nervioso, con una consecuente perturbación en la determinación cinética. En ausencia de un problema de este tipo, el hecho de no lograrse una socialización completa implicaría que la cima de esta dialéctica epigenética-cinética no se logra en todos sus niveles potenciales de libertad. Y por tanto, debe recordarnos, que el desarrollo del sistema nervioso 
sigue un proceso universal de estructuración luego del nacimiento, y que en tanto no ocurra esta estructuración (por privación de la socialización, por ejemplo) pueden verse afectados, de modo definitivo, la formación de estructuras preconscientes o neocorticales.

\section{Referencias}

1. Denegri MA. Somos protéticos. El comercio [Internet]. 21 de abril de 2014. 2. Palfrey J, \& Gasser U. Born Digital: Understanding the First Generation of Digital Natives. New York: Basic Books; 2010.

3. Moya-Salazar J, Rojas-Zumaran V. Tendencias en la investigación del Virus de Papiloma Humano en Latinoamérica y en los en los países de altos ingresos. Rev Col Obst Gin. 2017; 68(3):128-34

4. García JE, García E, García-Merino E. Tuberculosis y cine. Una aproximación a través de la fantasía de más de 400 películas. Rev Med Cine 2010; 6(3): 91-346. 5. Wagner R, Holliday A. Kaposi's Sarcoma in Film. J Med Mov. 2013; 9(3): 10713.

6. Baños JE, Aramburu JF, Sentí M. Biocinema: la experiencia de emplear películas comerciales con estudiantes de Biología. Rev Med Cine 2005; 1(2): 42-6.

7. Gonzáles P. Cine y profesionalismo médico: una reflexión ilustrada con cuatro películas de Steven Spielberg. Rev Med Cine 2019; 15(1): 25-31.

8. Astudillo W, Mendinueta C. El cine en la docencia de la medicina: cuidados paliativos y bioética. Rev Med Cine 2007; 3(1): 32-41.

9. Peña Iñaki. Cuidados paliativos y Cine: una actualización comentada de la producción relacionada desde mediados del siglo pasado hasta la última década del actual. Rev Med Cine 2018; 14(4): 259-65.

10. Valero M, Pérez J. Cine y práctica reflexiva. Una experiencia en los estudios de Medicina del Campus del Mar de Barcelona. Rev Med Cine 2018; 14(4): 253-8.

11. García-Sánchez JE, García-Sánchez E, García-Moro M. «La teoría del todo». Neurología: Esclerosis lateral amiotrófica. Rev Med Cine 2015; 11(2): 109-16.

12. García-Sánchez JE, García-Sánchez E. Enseñanza y cine: La neurología en Hollywood durante 2014. Rev Med Cine 2015; 11(1): 1-2.

13. Méndez-Domínguez N, Rodríguez-Castellanos A. Pertinencia del análisis de la película Contagio (2011) en el aprendizaje de la metodología clínica y epidemiológica en medicina. Rev Med Cine 2016; 12(3): 147-155.

14. Camacho JF. Epidemia: Un repaso a la fiebre hemorrágica por Ébola. Rev Med Cine 2013; 9(2): 70-81.

15. Wagner R. Teaching Skin Diseases to Medical Students through Film. J Med Mov. 2012; 8(1): 30-4

16. Fresnadillo MJ, Amado C, García-Sánchez E, García-Sánchez JE. Metodología docente para la utilización del cine en la enseñanza de la microbiología médica y las enfermedades infecciosas. Rev Med Cine 2005; 1(1): 17-23.

17. Ogando-Díaz B. Geriatría y cine: una mirada desde la salud. Rev Med Cine 2016; 12(4): 196-204.

18. Hidalgo A. Algunas características generales de los textos literarios realacionados con la enfermedad. Rev Med Cine 2016 ; 12 (2): 78-81.

19. Denegrí MA. Polimatía. Lima: Universidad Inca Garcilaso de la Vega; 2014 20. Contreras-Pulache H, Espinoza-Lecca E, Sevillano-Jimenez. Apuntes sobre la evaluación de la obra de Pedro Ortiz Cabanillas y su Teoría Sociobiológica Informacional. Rev Per Med Exp Salud Publica. 2018; 35(4):699-706.

21. Ortiz P. Psicobiología Social (tomo 1). 1ed. Lima: Fondo Editorial de la Universidad de Ciencias y Humanidades; 2017.

22. Ortiz P. Psicobiología Social (tomo 2). 1ed. Lima: Fondo Editorial de la Universidad de Ciencias y Humanidades; 2017.

23. Ortiz P. Psicobiología Social (tomo 3). Lima: Fondo Editorial de la Universidad de Ciencias y Humanidades; 2017.

24. Ortiz P. El Sistema de la Personalidad. 2ed. Lima: Fondo Editorial de la Universidad de Ciencias y Humanidades; 2016

25. Glasser M, Coalson T, Robinson E, Hacker C, Harwell J, Yacoub E, et al. A multimodal parcellation of human cerebral cortex. Nature 2016; 536(7615): 171-8.

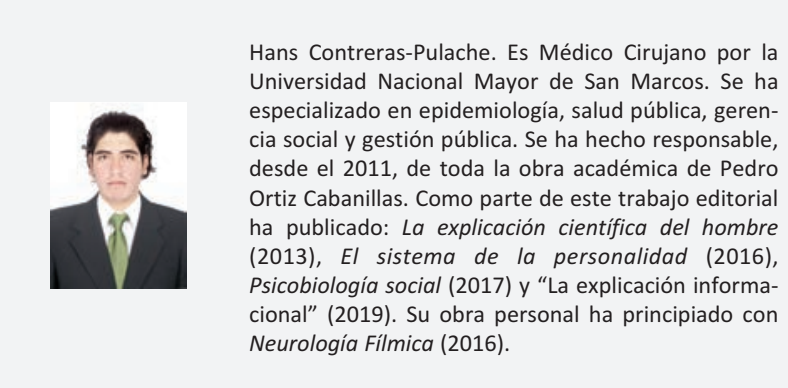

Alexa Ivonne Joya Quispe. Estudiante peruana de medicina de 3er año de la Universidad Privada Norbert Wiener. Apasionada por la cardiología y la investigación científica. Actualmente, es ejecutiva de Publicidad de Imoerio Peru Bussiness.
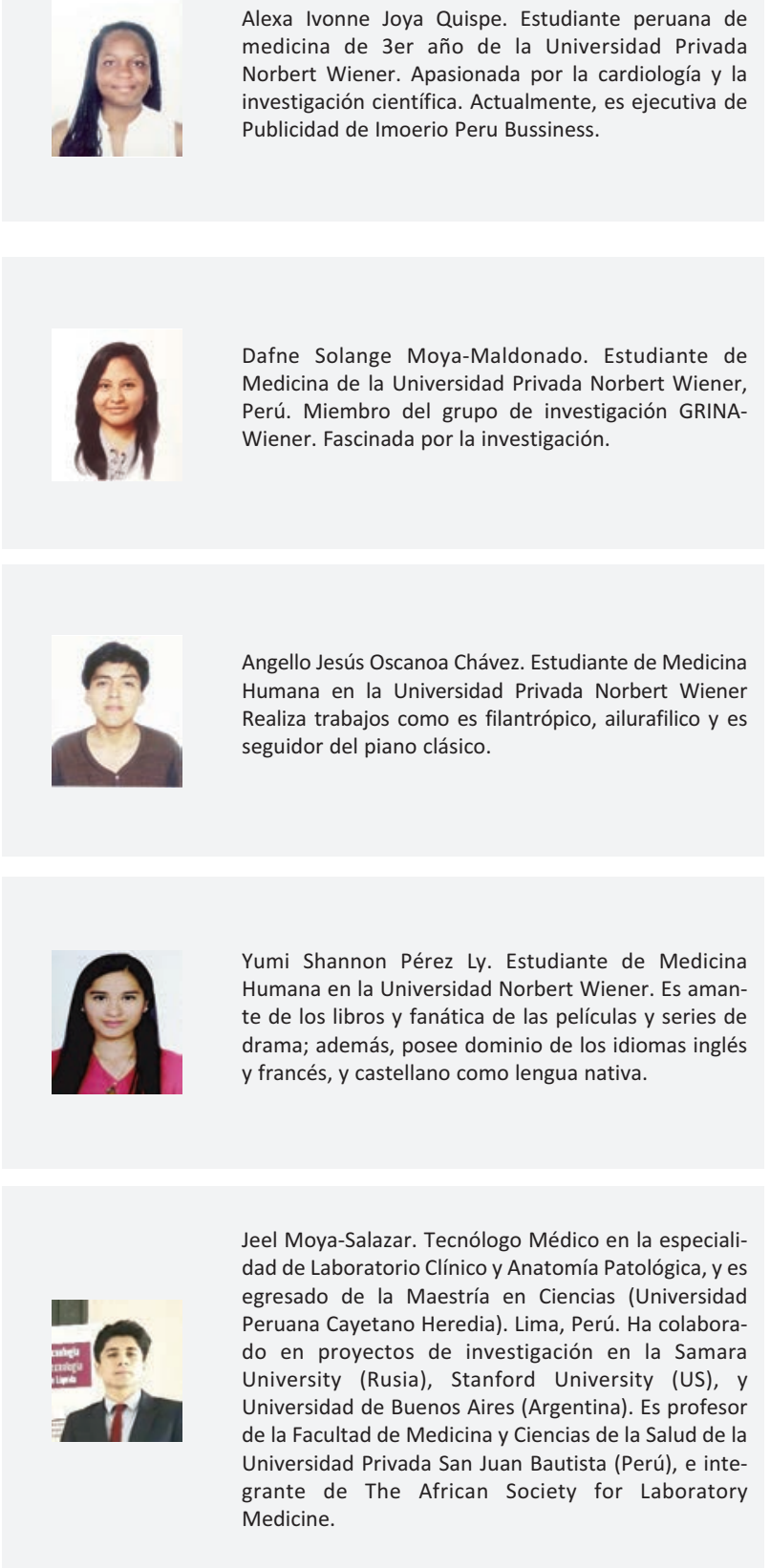